\title{
Operative intra-aortic balloon rupture
}

Rupture of an intra-aortic ballon ( $A B B$ ), inserted to assist in weaning from cardiopuimonary bypass, occurred during at rempred insra-aortic administration of protamine in a 71 -yearold male who later died. Intra-aortic balloon counterpulsation (IABC) is most commonly witized to assist in weaning from cardiopuimonary bypass (CPB) or to augment low-flow stales following $C P B$. In-hospital survival following IAB insertion in these circumstances in patients with coronary artery disease is approximately 60 per cent. Patients with valvular disease have a lawer in-hospital survival rate ( 50 per cent). Complications of $I A B C$ are usually of vascular or infectious origir. Balloon rupture is a rare though potentially lethal complication. The effects of balloon rupture may be compounded by the use of helium as a driving gas to inflate the balloon. Intra-aoric administration of prosamine has not been shown to be superior to peripheral administration and should be avoided if an $l A B$ is in place.

Intra-aortic balloon counterpulsation (IABC) is a valuable and accepted method of atugmenting the failing heart when the cause is potentially reversible. The intra-aortic balloon (IAB) is usually inserted via the femoral artery and placed in the descending thoracic aorta just distal to the left subclavian artery. Inflation of the IAB during diastole increases mean diastolic blood pressure and augments coronary artery diastolic blood flow. Deflation of the IAB in systole decreases left ventricular afterload and consequently myocardial oxygen consumption. ' Indications for IABC include unstable angina, reversable mechanical cardiac defects (acute mitral regurgitation and ventricular septal defect), pre-coronary artery by-pass stabilization, weaning from cardiopulmonary bypass (CPB) and cardiogenic shock. ${ }^{2}$

This is a report of an unusual complication of LABC in the weaning of a patient from cardiopulmonary bypass.

\section{Key words}

SURGERY: cardiac; TECHNIQUES: intra-aortic balloon counterpulsation; COMPL[CATIONS: gas embolism.

From the Department of Anaesthesia, University of Alberta, Edmonton, Alberta.

Address correspondence to: Dr. B.A. Finegan, Department of Anaesthesia, University of Alberta Hospital, Edmonton, Alberta, T6J 1E9

\section{Case report}

A 71 -year-old, $75 \mathrm{~kg}, 156 \mathrm{~cm}$ male presented with unstable angina for coronary artery bypass grafting. He gave a history of increasing incidence of anterior chest pain in the three months prior to admission which was resistant to medical therapy. Eight years previously he had an inferior wall myocardial infarction from which he had recovered without incident. The past history was otherwise unremarkable. Coronary angiography confirmed the presence of severe coronary discase with a 90 per cent occlusion of the LAD, a 95 per cent occlusion of the RCA and a 40 per cent occlusion of the left main coronary artery. Posterior and basal hypokinesis was noted.

The patient arrived in the operating room pain-free and arterial and pulmonary artery monitoring lines were inserted without difficulty. Base line haemodynamic data obtained prior to induction of anaesthesia revealed a low cardiac index with a normal systemic vascular resistance. Anaesthesia was induced with sufentanil $\left(20 \mu \mathrm{g} \cdot \mathrm{kg}^{-1}\right)$ supplemented by diazepam $\left(50 \mu \mathrm{g} \cdot \mathrm{kg}^{-1}\right)$. A combination of metocurine and pancuronium was used to provide muscle relaxation.

The patient underwent triple coronary artery revascularization uneventfully. Difficulty, however, was cxperienced in weaning from $\mathrm{CPB}$, due to severe right ventricular dysfunction, as evidenced by a markedly hypokinetic right ventricle and elevated right heart filling pressures (CVP $18 \mathrm{mmHg}$ ). A second weaning attempt after a period of rest on CPB was initially successful, but despite infusions of both dopamine $\left(15 \mu \mathrm{g} \cdot \mathrm{kg}^{-1} \cdot \mathrm{min}^{-1}\right)$ and dobutamine, $15 \mu \mathrm{g} \cdot \mathrm{kg}^{-3} \cdot \min ^{-1}$, adequate circulation could not be maintained. CPB was reinstituted and a Kontron 9.5 F IAB was inserted percutaneously via the right common femoral artery and connected to a Kontron K2000 pump using helium as the driving gas. The IAB was thought to be positioned in the descending thoracic aorta, distal to the origin of the left subclayian artery. The insertion length of the IAB was estimated by measuring the distance between the clavicle and the femoral artery. There was insufficient time for radiological conformation of its position. With the assistance of IABC and continued administration of dopamine and dobutamine, the patient was successfully weaned from CPB. After a 20-minure period of low-normal but stable haemodynamic parameters the venous cannula was removed. Two attempts were made to administer protamine directly into the ascending 
aorta using a $60 \mathrm{ml}$ syringe containing the appropriate dose of protamine, connected to a 1.5 inch 22-gauge needle, but on both occasions a bubble was noted in the fluid after the needle had been inserted into the aorta. Intra-aortic protamine administration was abandoned and the syringe was passed to the anaesthetist for intravenous administration.

At this lime a gas bubble was noted in the aortic perfusion tubing. Seconds later several more bubbles were noted and the patient's blood pressure fell precipitously. A diagnosis of $I A B$ rupture was made and as IABC was discontinued and the IAB removed, cardiac massage was instituted. The patient was placed head down and pressure was applied over the carotid arteries. The aortic perfusion cannula was disconnected from its tubing to allow back bleeding and gas evacuation. The venous cannulae were replaced and CPB recommenced. Visual inspection of the IAB following removal revealed two holes near its tip and blood in the tubing. Attempts to insert a replacement $I A B$ via left or right femoral arteries were unsuccessful. However, with infusion of dopamine $\left(10 \mu g \cdot \mathrm{kg}^{-1} \cdot \mathrm{min}^{-1}\right)$, dobutamine $\left(15 \mu \mathrm{g} \cdot \mathrm{kg}^{-1} \cdot \mathrm{min}^{-1}\right)$, epinephrine ( $\left.4 \mu \mathrm{g} \cdot \mathrm{min}^{-1}\right)$ and calcium ( $\left.1 \mathrm{mg} \cdot \mathrm{min}^{-1}\right)$, it was possible to wean the patient from $C P B$ and close the chest.

The patient was transferred to the Intensive Care Unit where, within one hour, he had a cardiac arrest from which he could not be resuscitated. Consent for autopsy was refused.

\section{Discussion}

The most common indication for IABC is to assist in weaning of patients from $C P B$ and to augment cardiac output in post-CPB low output states. ${ }^{3,4}$ IABC in this setting is associated with in-hospital survival rates of 60 per cent in patients with coronary artery disease as the preoperative diagnosis. $^{5}$

Lower in-hospital and long-term survival rates are seen where valve replacement is the indication for surgery. This is particularly so with IABC post-aortic valve replacement for aortic incompetence where the one year survival is only 13 per cent. ${ }^{6}$

Complications associated with IABC may occur in up to $\mathbf{4 5}$ per cent of patients. ${ }^{\top}$ The majority are minor and resolve with removal of the $\mathrm{IAB}$ being related to the vascular status of the patient.

Complications can be classified into three categories: those related to insertion, use, and removal of the balloon. Insertion may be associated with failure to pass the balloon, aortic dissection and/or perforation. When the balloon is in place and operating: limb ischaemia, local or systemic infection, embolization, balloon rupture and thrombocytopaenia may occur. Following removal hematoma formation or bleeding at the insertion site and femoral antery thrombosis have been described.

Infectious complications are reduced by percutaneous insertion of the $\mathrm{IAB},{ }^{8}$ but this may increase the risk of vascular damage. ${ }^{4}$ Should vascular damage occur, early recognition and repair is essential. ${ }^{9}$

Balloon rupture is a rare but potentially disastrous complication of IABC. ${ }^{10}$ In this case it was noted immediately by the detection of gas in the aortic line but in other reported cases the hallmark of rupture has been the presence of blood in the balloon tubing and an alteration in the configuration of the balloon pressure curve. ${ }^{11,12}$ Damage to the balloon at insertion or during the process of inflation and deflation by atheromatous plaque is thought to cause balloon nupture. The overall incidence of balloon rupture is reported to be 0.12 and 1.3 per cent. ${ }^{13}$

In the case described, rupturc appears to have been caused by the accidental insertion of a needle into the IAB in an attempt to administer protamine into the ascending aorta. This would imply that a part of the IAB was positioned in ascending aorta. In this case one would have expected to have seen an alteration in the left radial waveform, but this did not occur. Indeed, when the surgeon directly measured the pressure in the ascending aorta to rule out a disparity between the aortic and peripheral arterial pressures, the aortic pressure waveform obtained was virtually identical to the left radial arterial waveform. Accidental placement of an IAB in the left subclavian artery with a normal left radial pulse after insertion has been reported. ${ }^{14}$ Factors thought to encourage cephalad migration of the IAB include assumption of the sitting position and flexion of the lower limb at the site of $1 \mathrm{AB}$ insertion. ${ }^{15}$ Neither of these factors were present in our case.

The driving gas used in IABC devices can be either helium or carbon dioxide. Helium is less dense than air or carbon dioxide and so provides a faster response time during the process of inflation and deflation. This should theorctically result in a steeper rise and fall in diastolic augmentation pressure with a consequent enhancement of diastolic coronary perfusion. Helium is, however, less soluble in blood than air and presents an added hazard should it enter the circulation. Carbon dioxide is 80 times as soluble as helium and 34 times as soluble as air, diffusing into blood faster than any other gas. ${ }^{13}$ For this reason it may be the safest driving gas for IABC. The use helinm as the driving gas in our case may have exacerbated the consequences of balloon rupture.

The direct intra-aortic administration of protamine has not been shown to offer any clinical advantage over judicious peripheral intravenous administration ${ }^{16,17}$ and in particular does not modify the incidence or severity of 
pulmonary vasoconstriction occasionally seen with the use of protamine. $^{18}$

We would advise that instrumentation of the aorta in the presence of an IAB be avoided and constant vigilance maintained for the signs of balloon nupture - a potentially fatal event - during IABC therapy.

\section{References}

1 Kafrouni $G$. Intra Aortic Balloon Counterpulsation. Am J Surg 1984; 147: 731-4,

2 Cutler BS. The Intra Aortic Balloon and Counterpulsation. in: Rippe JN, Irwin RS, Alpert JS, Dallen JE (Eds). Intensive Care Med, 1st Ed, Alston, Toronto: Little Brown \& Co. 1985; 104-14.

$3 O^{\prime}$ Rourke $M$. Intraaortic halloon assistance Lur Heart $]$ 1986; 7: 400-3.

4 Goldberger $M$, Tabak SW, Shah $P K$. Clinical experience with intractic balloon counterpulsation in 112 consecutive patients. Am Heart J 1986; 111: 497-502.

5 Sanfelippo $P M, B a k e r N H, E w y H G$ et al. Experience with intraaortic balloon counterpulsation. Ann Thorac Surg 1986; $41: 36-41$.

6 Downing TP, Miller DC, Stofen R. Shumway NE. Use of the intra-aortic balloon pump after valve replacement. $J$ Thorac Cardiovasc Surg 1986; 92: 210-7.

7 Kantrowits A, Wasfie T. Feed P et al. Intraaortic balloon pumping 1967 through 1982: analysis of complications in 733 patients. Am J Cardiol 1986; 57: 976-83.

8 Collier PE, Liebler GA, Park SB et al. Is percutaneaus insertion of the intra-aortic balloon pump through the femoral artery the safest technique? I Vasc Surg 1986; 3: 629-34.

9 Mills $J L$, Wiedeman JE, Rabison JG, Hallet JW. Minimizing mortality and morbidity from iatrogenic arterial injuries: the need for early recognition and prompt repair. J Vasc Surg 1986; 4: 22-7.

10 Mayerhofer, KE, Billhardt RA, Codini Ma. Delayed Abrasion Perforation of Two Intra Aortic Balloons. Am Heart J 1984; 108: 1361-3.

11 Gonzalez M, Installe E, Tremouroux J. Percutaneous intra aortic balloon pumping: initial experience. Intensive Care Med 1982:8: 143-7.

12 Goulieb SO. Brinker JA. Borkon M et al. Identification of patients at high risk for complicutions of intra aortic balloon counterpulsation: a multi varied risk factor analysis. Am J Cardiol 1984; 53: 1135-9.

13 Kayser KL, Johnson WD, Shore RT. Comparison of driving gases for IABPs. Medical Instrumentation 1981; 15: $51-4$.

14 Rodger PC, Bridges KG. Occlusion of left internal mammary artery with intra-gortic balloon: clinical implications. J Thorac Cardiovase Surg 1986; 91; 141-9.
$15 O^{\prime}$ Rourke $M F$, Shepherd $K M$. Protection of the aortic arch and subclavian artery during intra-aortic balloon pumping. J Thorac Cardiovasc Surg 1973; 65: 543-6.

16 Horrow JC. Protamine: a rewiew of its toxicity. Anesth Analg 1985; 64: 348-61.

17 Milne B, Rogers $K$, Cervenko F, Salerno $T$. The haemodynamic effects of intra aortic versus intravencus administration of protumine for reversal of heparin in man. Can Anaesth Soc J 1983; 30: 347-51.

18 Lowenstein E, Johnston WE, Lappas DG et al. Catastrophic pulmonary vasoconstriction associatcd with protamine reversal of heparin. Anesthesiology 1983; 59: $470-3$.

\section{Résumế}

La rupture d'un bullon intra aorlique (IAB), inséré afin de faciliter la sortie de CEC (circulation extra corporelle) est survenue après tentative d'administration intra aoriique de protamine chez un patient agé de 7 l ans qui décéda par la suite. Le ballon intra aortique (IABC) est souvent utilise afin de faciliter le sevrage de la CEC (CPB) ou d'augmenter le débit après la CEC. La survie après insertion de ballon intra aortique dans ces circonstances chez des patients atteints de moladie coronarienne est approximativement 60 pour cent. Les patients atteints de maladie valvulaire ont une survie moindre d'd peu près 50 pour cent. Les complicarions du ballon intra aortique sont habituellement d'origine vasculaire ou infectieuse. La rupture du ballon est rare et peut erre possiblement mortelle. Les effets de la rupture du ballon peuvent etre compliqués par l' utilisation de l' hélikm pour gonfler les ballons. L'administration intra aortique de protamine n'a pas été demontrée supérieure à son administration par voie periphérique et doit etre évitée si un ballon intra aortique est en place. 